\title{
CMEARTICLE
}

\section{Wheeze in childhood: is the spacer good enough?}

\author{
Veena Rajkumar ${ }^{1,3,4}$, MBBS, FRCPCH, Barathi Rajendra ${ }^{1,3,4}$, BMBS, FRCPCH, Choon How $\underline{\text { How }}^{2}$, MMed, FCFP, \\ Seng Bin $\overline{\text { Ang }^{1,3}}$, MMed, FCFP
}

Max's parents brought him to see you for cough and wheezing. Three-year-old Max had a tendency to wheeze whenever he had respiratory infections. This was his second episode of wheeze; his first episode last year was managed at the children's emergency department. Max also had mild eczema and his father used to have childhood asthma. At this presentation, he had bilateral wheeze on auscultation and mild intercostal recessions, but was otherwise active and cheerful. Max's parents expressed concern about the need for nebulisers to treat his wheeze.

\section{HOW RELEVANT IS THIS TO MY PRACTICE?}

Wheezing in children is one of the most common chronic problems in childhood encountered by medical professionals in all healthcare settings. The prevalence of childhood asthma is high $(8.9 \%)$, and the majority of asthmatic children are managed in the primary care setting. ${ }^{(1)}$ The high prevalence of wheezing in children can be attributed to the increasing trends of atopic disease in the region, as well as the well-known association between allergy and asthma. ${ }^{(2)}$

Inadequate control is a common issue when it comes to management of wheeze in childhood in the community, and this in turn poses a significant challenge to primary care physicians. Appropriate management, including correct inhalational technique, is crucial to acute and long-term outcomes. Today, the inhalation method is the recommended administration route for acute management of wheeze. Although the characteristics of various drug delivery systems, including drug dose delivery, feasibility of use and age appropriateness, have been extensively studied, the perfect inhalation device still eludes us. Pressurised metered dose inhalers (MDIs) and spacers have been available for many decades. This article analyses the established evidence in support of the use of MDI with spacers (MDI+S) over nebulisers for the management of wheeze in children. Other aerosol delivery methods and pharmacological management of asthma are not discussed in this article.

\section{AEROSOLS AND THEIR IMPORTANCE IN ASTHMA MANAGEMENT}

Aerosols are liquid or solid particles suspended in a carrier gas. Aerosol administration is painless and convenient, delivering adequate concentrations of the drug directly into the lung.(3) It has quicker onset of action and is categorically better than the systemic route. ${ }^{(4)}$
Table I. Errors in the use of nebuliser devices (adapted from Hess ${ }^{(3)}$ ).

\begin{tabular}{l}
\hline Nebuliser: user errors \\
\hline - Improper assembly of the device \\
- Incorrect flow or fill volume \\
- Spillage caused by tilting of the nebuliser \\
- Failure to keep the mouthpiece in the mouth during nebulisation \\
- Leaks around the facemask
\end{tabular}

\section{What are the different aerosol delivery devices? Nebulisers}

Nebulisers have been the traditional aerosol delivery mechanism for many decades. They work on the Venturi principle, where negative pressure is used to create aerosol from a drug suspension. The original nebuliser has undergone several modifications, and these include the pneumatic jet nebuliser, ultrasonic nebuliser and mesh nebuliser, with differences in aerosol droplet size, respirable dose, nebulisation time, ease of cleaning, sterilisation and costs. ${ }^{(3)}$ The well-known disadvantages of nebulisers include feasibility of use, cost and side effects of medication, namely tachycardia in the case of short-acting beta-2 agonists (SABA). Errors in the use of the nebuliser by patients, caregivers or nurses could compromise drug delivery and treatment efficacy (Table I). ${ }^{(3)}$

\section{Pressurised metered dose inhalers}

MDIs, the most commonly used aerosol delivery devices, have the following advantages: small size; portability; low cost; and convenience of use. ${ }^{(3)}$ The key components of an MDI device are the canister, propellant, drug formulation, metering valve and actuator. The drug is stored as either a solution or a suspension. The metering valve helps in drug dosing and the actuator aids the formation of aerosol. Shaking and priming of the MDI before use is vital for effective drug delivery. Commonly used MDIs are shown in Fig. 1.

The downside of $\mathrm{MDI}$ is its capacity to deliver only a fraction of the dose to the lungs. This can be as low as $10 \%$, especially

${ }^{1}$ Department of Paediatric Medicine, KK Women's and Children's Hospital, ${ }^{2}$ General Medicine, Changi General Hospital, ${ }^{3}$ Duke-NUS Graduate Medical School, ${ }^{4}$ Yong Loo Lin School of Medicine, National University of Singapore, Singapore

Correspondence: Dr Ang Seng Bin, Head, Family Medicine Service and Menopause Unit, KK Women's and Children's Hospital, 100 Bukit Timah Road, Singapore 229899. ang.seng.bin@kkh.com.sg 


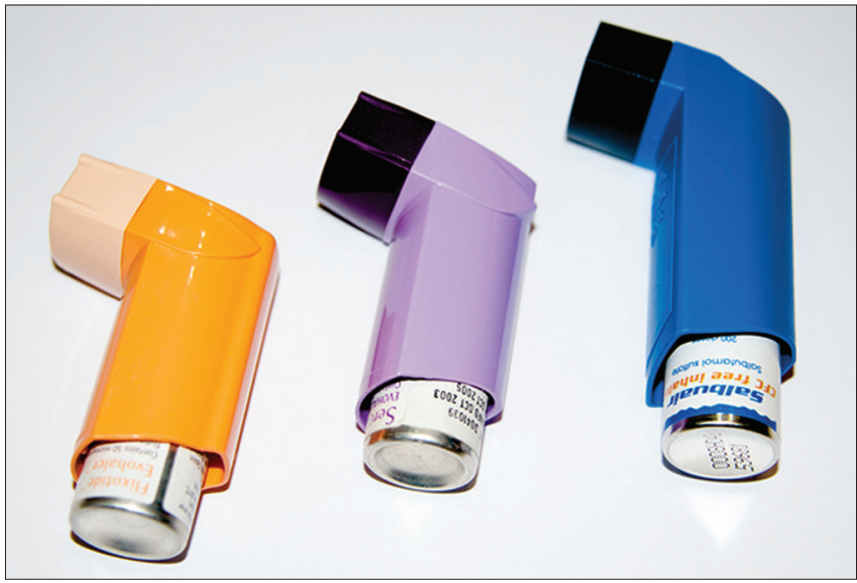

Fig. 1 Photograph shows commonly used pressurised metered dose inhalers. Short-acting beta-2 agonists, namely salbutamol (commonly called 'reliever'), are made available in shades of blue.

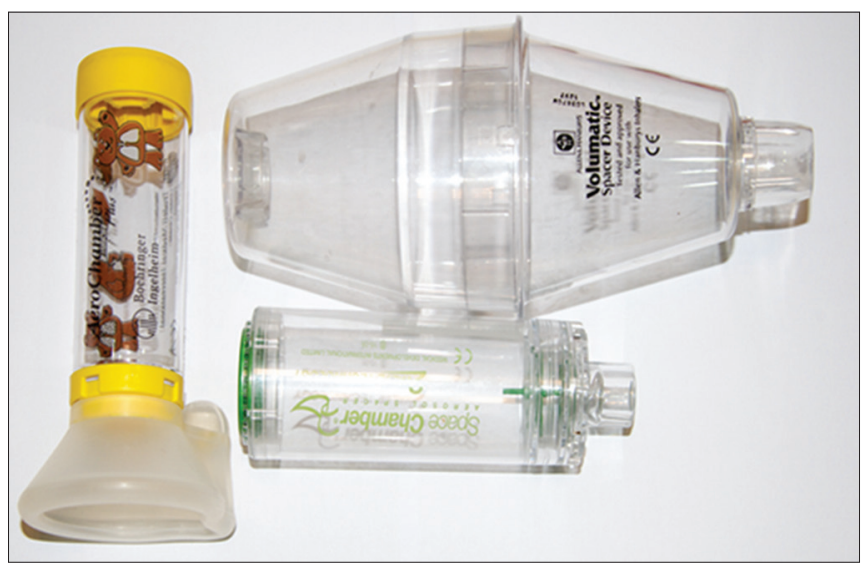

Fig. 2 Photograph shows various types of spacers available for paediatric use with metered dose inhalers.

with incorrect technique of hand-breath coordination. ${ }^{(5)}$ With up to $80 \%$ of the dose being deposited in the oropharynx, the risks of systemic absorption and side effects are increased. About $15 \%$ of patients are unable to use the correct technique despite appropriate training (Table II). ${ }^{(5,6)}$ The delivered dose could be compromised by around $25 \%$ if the MDI device is stored stem down and not adequately shaken prior to use. ${ }^{(7)}$ Furthermore, the most commonly used MDI devices require the patient to manually count the number of doses inhaled, resulting in the possibility of using beyond the capacity of the device. Integrated dose counters can help to keep track of the remaining available actuations. ${ }^{(8)}$ In older children above six years of age, the problem of hand-breath coordination can be minimised by the use of breath-actuated MDIs or autohalers. ${ }^{(9)}$ These devices sense the patient's inhalation and automatically initiate the actuation, which in turn increases lung deposition. ${ }^{(10)}$

\section{Valved holding chambers/spacers}

Valved holding chambers (VHC) and spacers are holding chambers with an MDI at one end and a mask or mouthpiece at the other end (Fig. 2). They facilitate the effective use and drug delivery of MDIs. $\mathrm{VHC}$ is an extension device with one
Table II. Errors in the use of MDIs (adapted from Hess ${ }^{(3)}$ ).

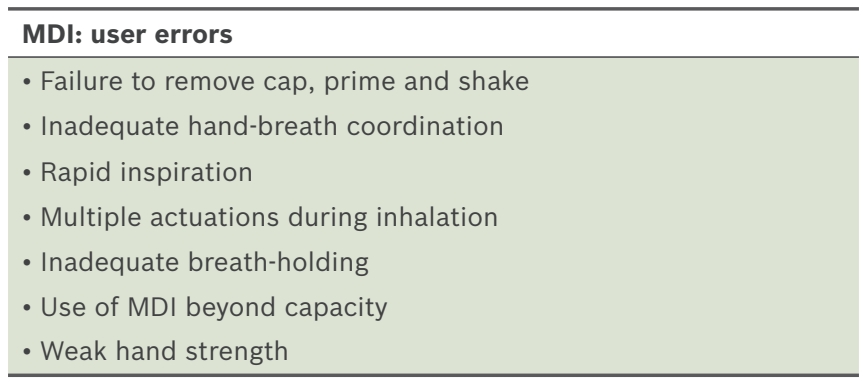

MDI: metered dose inhaler

Table III. Factors contributing to inconsistent medication delivery with spacers. $^{(12,14)}$

\begin{tabular}{|c|c|}
\hline Device-related factors & Patient-related factors \\
\hline $\begin{array}{l}\text { - Electrostatic charge: } \\
\text { associated with aerosol and } \\
\text { interior surfaces of the spacer }\end{array}$ & $\begin{array}{l}\text { - Choice of appropriate } \\
\text { spacer and patient interface } \\
\text { (mouthpiece or facemask) }\end{array}$ \\
\hline - Inhalation valve dysfunction & - Patient inhalation technique \\
\hline $\begin{array}{l}\text { - Size of spacer in relation to } \\
\text { patient's breathing pattern }\end{array}$ & - Disease modality and severity \\
\hline - Facemask-to-face seal integrity & - Incorrect assembly of the device \\
\hline
\end{tabular}

Table IV. Ways to minimise inconsistent delivery and optimise aerosol delivery. ${ }^{(14)}$

Factors that optimise medication delivery with spacers
- Compact size to minimise the number of inhalations to empty
chamber
- Responsive inhalation and exhalation valves
- Capability to observe valve movement
- Ability to ensure good facemask seal to the face
- Age-specific designs for infant, child or adult use
- Facemask with minimal dead volume and comfortable fit
- Exhalation valve in facemask to decrease rebreathing
- Clear instructions for cleaning at regular intervals

way valves to aid delivery during inspiration, prevent wastage during expiration, ${ }^{(3)}$ and reduce the coordination problems often encountered when using MDIs. ${ }^{(4)}$ Currently, most spacers are $\mathrm{VHCs}$ and the two terms tend to be used interchangeably. Newman et al demonstrated that the use of $\mathrm{MDI}+\mathrm{S}$ produces a greater lung drug deposition (15\%), which is a statistically significant increase compared to the use of only MDI with good technique $(11 \%){ }^{(11)}$

The disadvantages of the spacer are its size and portability, errors of assembly, and loss of aerosol drug particles due to inertial impaction and gravitational sedimentation. ${ }^{(12)}$ Delays between actuation and inhalation, ${ }^{(13)}$ and electrostatic charges in a new chamber device can reduce the emitted dose of the aerosol. Table III outlines the factors that contribute to inconsistent medication delivery with a spacer, while Table IV enumerates the ways of optimising medication delivery while using a spacer.

Patients and caregivers should be advised on the proper care of the spacer device as such:

1. The spacer should be primed before the first use to reduce electrostatic charges. 


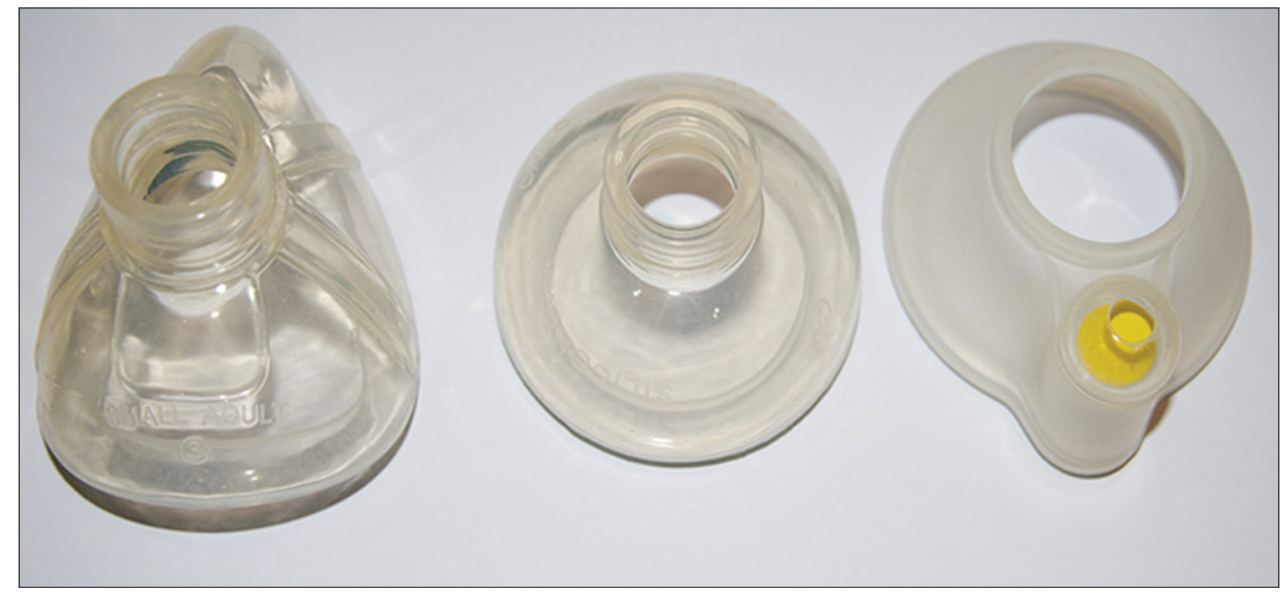

Fig. 3 Photograph shows various types of facemasks available for paediatric use. Choice of mask depends on the type of spacer and the age of the child.

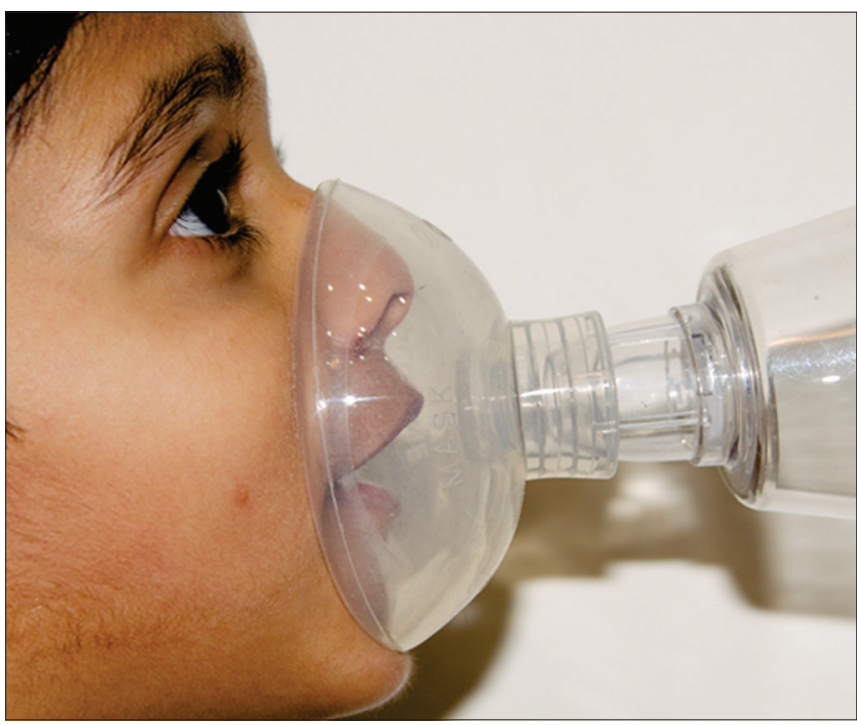

Fig. 4 Photograph shows a child employing an appropriate technique with good seal while using an aerosol device.

2. Every few weeks, the spacer should be cleaned gently with warm mild soapy water and dripped dry.

3. Vigorous rinsing and towel drying should be avoided, as these may reintroduce static.

4. Spacers should be replaced every 6-12 months and are recommended for use by only one person.

\section{Does my patient require a facemask?}

Younger children, especially those under five years of age, need a facemask attached to the mouthpiece, as they may be unable to produce a tight seal around the mouthpiece. ${ }^{(3,14)}$ Fig. 3 shows the commonly used types of facemasks in paediatric use. For effective administration of aerosol medication, a good facemask seal should be obtained (Fig. 4). ${ }^{(15)}$

\section{Can spacers be used in the treatment of mild to moderate exacerbations of wheeze?}

From the early 1990s, MDI+S has been used to deliver SABA in mild to moderate exacerbations of asthma in children, and found to be as effective as nebuliser treatment. ${ }^{(16)}$ The 2013
Cochrane database systematic review ${ }^{(17)}$ compared the efficacy of spacers vs. nebulisers for delivery of SABA in 1,897 children and 729 adults across 39 trials in community, emergency and inpatient settings. The review found no difference in outcomes (peak flow and forced expiratory volumes) between the two delivery methods. The use of $\mathrm{MDI}+\mathrm{S}$ in children resulted in a significant reduction in emergency department treatment time (33 min less; 95\% confidence interval $[\mathrm{Cl}]-43$ to -24 min). Pulse rate was lower in children (mean difference $-5 \%$ baseline; $95 \%$ $\mathrm{Cl}-8 \%$ to $-2 \%$ ), as was the risk of developing tremor (relative risk 0.64; 95\% Cl 0.44-0.95). ${ }^{(17)}$ Another meta-analysis showed that children younger than five years of age with acute moderate to severe wheeze experienced reduced hospital admission with the use of $\mathrm{MDI}+\mathrm{S}$ (odds ratio $0.42 ; 95 \% \mathrm{Cl} 0.24-0.72$ ). ${ }^{(18)}$

It can therefore be safely concluded that the use of $\mathrm{MDI}+\mathrm{S}$ in the treatment of acute wheeze in children requiring SABA (excluding life-threatening exacerbations) is safe and effective.

\section{Have spacers been found to be effective in the local healthcare setting?}

A study by Goh et al found no significant increase in admissions and a reduction in readmissions with the use of $\mathrm{MDI}+\mathrm{S}$ as compared to nebulisers. ${ }^{(19)}$ There was also a reduction in cost, as previously established ${ }^{(20)}$ and a shorter hospital stay. ${ }^{(21)}$ Indeed, the reduction in emergency department time with the use of $\mathrm{MDI}+\mathrm{S}$ is of value in the management of acute paediatric wheeze exacerbations. ${ }^{(19,22)}$

\section{Is there a role for nebulisers in my practice?}

Aerosol therapy with nebuliser is logistically complicated and time consuming, with a child required to sit still for at least $5 \mathrm{~min}$. $\mathrm{MDI}+\mathrm{S}$, on the other hand, requires a shorter administration time, yields a higher compliance rate ${ }^{(23)}$ and leads to better patient coordination. ${ }^{(24)}$ Financial implications also favour the use of $\mathrm{MDI}+\mathrm{S}$, which provides the advantages of practicality, lower costs and multiple dose usage. ${ }^{(25)}$ Lower deposition of drug and fewer systemic side effects (namely tachycardia with SABA) categorically sway the balance toward MDI+S. ${ }^{(24,26)}$ Well-recognised guidelines such as the Global Initiative for 
Asthma (GINA) and British Thoracic Society (BTS) guidelines now recommend the use of $\mathrm{MDI}+\mathrm{S}$ for the management of acute wheeze in children, and nebulisers are no longer recommended or required for mild/moderate exacerbations.

\section{Can I use oral salbutamol in my practice?}

Due to its quicker onset of action and fewer side effects, the inhaled route has been categorically established as the recommended choice for more than a decade.(4) Oral SABA, namely syrup salbutamol, is not recommended in the management of acute wheeze in children because of the risk of systemic side effects. $\mathrm{MDI}+\mathrm{S}$ is currently the modality of choice for the delivery of bronchodilator drugs.

\section{Can spacers be used for all age groups?}

For preschool children aged between 1-5 years old, there is categorical evidence for the use of $\mathrm{MDI}+\mathrm{S}$ instead of nebulisers for the management of acute wheeze with SABA. Specific randomised studies in this age group have reported a shorter recovery time and greater efficacy with the use of a spacer. ${ }^{(23,27)}$ The benefit of $\mathrm{MDI}+\mathrm{S}$ is also proven in older children aged above five years. ${ }^{(28)}$ Although other options such as dry powder inhalers and breath-actuated devices are also used in this age group, $\mathrm{MDI}+\mathrm{S}$ is still the recommended method in an acute asthma exacerbation, as it does not require the patient to exercise hand-breath coordination (which is vital for efficacious use in other aerosol devices).

The use of bronchodilators in infants is a controversial and debatable topic. However, systematic reviews and specific studies have shown the advantage of $\mathrm{MDI}+\mathrm{S}$ use in this age group, with reduced hospital admission rates reported. ${ }^{(18,29)}$ Therefore, when clinically indicated in older, cooperative infants, spacers can be used with MDIs to deliver bronchodilators in cases of mild to moderate wheeze.

Current evidence clearly shows that the use of $\mathrm{MDI}+\mathrm{S}$ can replace nebulisers in the treatment of acute non-life-threatening wheeze in all settings. There is also a good compliance rate (98\%), as reported by a large local paediatric hospital. ${ }^{(19)}$

\section{How vital is it to educate the patient/caregiver?}

Inappropriate usage of aerosol devices such as the MDI is associated with poor control. ${ }^{(3,30)}$ Hence, proper education of the patient/caregiver on the use of the aerosol device (Fig. 4) is important. The prescribing physician should also be familiar with the technique and constantly reinforce the importance of proper usage during every visit. Choice of an appropriate device, good communication and education can help to facilitate adherence to therapy and improve management in both acute and longterm patients. $^{(3)}$

\section{How to deal with uncooperative children?}

Technique and compliance is the key to optimal aerosol drug delivery. Crying and distressed children have less aerosolised drug deposition compared to those who are calm. ${ }^{(31)}$ Drug delivery with $\mathrm{MDI}+\mathrm{S}$ during sleep in young children is unpredictable and not feasible, and is therefore not recommended. ${ }^{(32)}$

\section{Can spacers be used in life-threatening exacerbations?}

The current evidence for the use of $\mathrm{MDI}+\mathrm{S}$ for SABA delivery does not include life-threatening wheeze exacerbations. ${ }^{(18)}$ The findings, therefore, cannot be extrapolated to the more severe, life-threatening episodes of wheeze; these cases should be managed in the hospital setting with appropriate expertise and intensive care backup.

\section{TAKE HOME MESSAGES}

1. MDI with spacer is the device of choice for the management of acute wheeze with inhaled SABA in children who are in non-life-threatening situations.

2. MDI with spacer can safely and efficiently replace the use of a nebuliser in the acute healthcare and home settings, except in very severe, life-threatening situations.

3. Ease of use, portability, affordability and reduced side effects of SABA are additional benefits of an MDI with spacer.

4. Children under five years of age should be provided with a facemask when using an MDI with spacer.

5. Compliance and long-term control are also shown to improve with the use of an MDI with spacer.

6. Appropriate patient/parent/caregiver education and training, with emphasis on compliance and technique at every visit, remains the key to the successful management of wheeze in childhood.

Max was treated with SABA using an MDI and spacer with facemask and responded well to the initial treatment. You explained to the parents that nebulisers are neither required nor recommended in the treatment of wheezing in their child's situation. You advised the parents on the proper technique of MDI use with spacer and facemask, as well as care of the equipment. You also gave them a clearly written action plan regarding the efficient management of the next episode of wheeze with MDI and spacer. You further explained the side effects of oral bronchodilators and nebulisers, and why you refrained from using them. Max was given a follow-up appointment to assess his progress, and his parents were advised on the situations when they should go to a doctor or the emergency department.

Keywords: asthma, bronchodilator, childhood wheeze, MDI, spacer

\section{REFERENCES}

1. Tan C, Wong B, Goh DY, Van Bever HP. Monitoring and treatment practices of childhood asthma in Singapore: a questionnaire study. Singapore Med J 2009; 50:54-61.

2. Chiang WC, Chen YM, Tan HK, et al. Allergic rhinitis and non-allergic rhinitis in children in the tropics: prevalence and risk associations. Pediatr Pulmonol 2012; 47:1026-33.

3. Hess DR. Aerosol delivery devices in the treatment of asthma. Respir Care 2008; 53:699-723; discussion 723-5.

4. Pedersen S, Dubus JC, Crompton GK, ADMIT Working Group. The ADMIT series - issues in inhalation therapy. 5) Inhaler selection in children with asthma. Prim Care Respir J 2010; 19:209-16. 
5. Konig P. Spacer devices used with metered-dose inhalers. Breakthrough or gimmick? Chest 1985; 88:276-84.

6. Appel D. Faulty use of canister nebulizers for asthma. J Fam Pract 1982 14:1135-8.

7. Everard ML, Devadason SG, Summers QA, Le Souef PN. Factors affecting total and "respirable" dose delivered by a salbutamol metered dose inhaler. Thorax 1995; 50:746-9.

8. Sheth K, Wasserman RL, Lincourt WR, et al. Fluticasone propionate/ salmeterol hydrofluoroalkane via metered-dose inhaler with integrated dose counter: Performance and patient satisfaction. Int J Clin Pract 2006 60:1218-24.

9. Pedersen S, Mortensen S. Use of different inhalation devices in children. Lung 1990; 168 Suppl:653-7.

10. Newman SP, Weisz AW, Talaee N, Clarke SW. Improvement of drug delivery with a breath actuated pressurised aerosol for patients with poor inhaler technique. Thorax 1991; 46:712-6.

11. Newman SP, Woodman G, Clarke SW, Sackner MA. Effect of InspirEase on the deposition of metered-dose aerosols in the human respiratory tract. Chest 1986; 89:551-6.

12. Rau JL. Practical problems with aerosol therapy in COPD. Respir Care 2006; 51:158-72.

13. Clark DJ, Lipworth BJ. Effect of multiple actuations, delayed inhalation and antistatic treatment on the lung bioavailability of salbutamol via a spacer device. Thorax 1996; 51:981-4

14. Mitchell JP, Nagel MW. Valved holding chambers (VHCs) for use with pressurised metered-dose inhalers (pMDIs): a review of causes of inconsistent medication delivery. Prim Care Respir J 2007; 16:207-14.

15. Smaldone GC, Berg E, Nikander K. Variation in pediatric aerosol delivery: importance of facemask. J Aerosol Med 2005; 18:354-63.

16. Chou KJ, Cunningham SJ, Crain EF. Metered-dose inhalers with spacers vs nebulizers for pediatric asthma. Arch Pediatr Adolesc Med 1995; 149:201-5.

17. Cates CJ, Welsh EJ, Rowe BH. Holding chambers (spacers) versus nebulisers for beta-agonist treatment of acute asthma. Cochrane Database Syst Rev 2013; 9:CD000052.

18. Castro-Rodriguez JA, Rodrigo GJ. Beta-agonists through metereddose inhaler with valved holding chamber versus nebulizer for acute exacerbation of wheezing or asthma in children under 5 years of age: a systematic review with meta-analysis. J Pediatr 2004; 145:172-7.

19. Goh AE, Tang JP, Ling H, et al. Efficacy of metered-dose inhalers for children with acute asthma exacerbations. Pediatr Pulmonol 2011; 46:421-7.

20. Leversha AM, Campanella SG, Aickin RP, Asher MI. Costs and effectiveness of spacer versus nebulizer in young children with moderate and severe acute asthma. J Pediatr 2000; 136:497-502.

21. Dewar AL, Stewart A, Cogswell JJ, Connett GJ. A randomised controlled trial to assess the relative benefits of large volume spacers and nebulisers to treat acute asthma in hospital. Arch Dis Child 1999; 80:421-3.

22. Staggs L, Peek M, Southard G, et al. Evaluating the length of stay and value of time in a pediatric emergency department with two models by comparing two different albuterol delivery systems. J Med Econ 2012; 15:704-11.

23. Ploin D, Chapuis FR, Stamm D, et al. High-dose albuterol by metered-dose inhaler plus a spacer device versus nebulization in preschool children with recurrent wheezing: A double-blind, randomized equivalence trial. Pediatrics 2000; 106(2 Pt 1):311-7.

24. De Benedictis FM, Selvaggio D. Use of inhaler devices in pediatric asthma. Paediatr Drugs 2003; 5:629-38.

25. Bowton DL, Goldsmith WM, Haponik EF. Substitution of metered-dose inhalers for hand-held nebulizers. Success and cost savings in a large, acute-care hospital. Chest 1992; 101:305-8.

26. Deerojanawong J, Manuyakorn W, Prapphal N, et al. Randomized controlled trial of salbutamol aerosol therapy via metered dose inhalerspacer vs. jet nebulizer in young children with wheezing. Pediatr Pulmonol 2005; 39:466-72.

27. Rubilar L, Castro-Rodriguez JA, Girardi G. Randomized trial of salbutamol via metered-dose inhaler with spacer versus nebulizer for acute wheezing in children less than 2 years of age. Pediatr Pulmonol 2000; 29:264-9.

28. Direkwatanachai C, Teeratakulpisarn J, Suntornlohanakul S, et al. Comparison of salbutamol efficacy in children - via the metered-dose inhaler (MDI) with Volumatic spacer and via the dry powder inhaler, Easyhaler, with the nebulizer - in mild to moderate asthma exacerbation: a multicenter, randomized study. Asian Pac J Allergy Immunol 2011; 29:25-33

29. Delgado A, Chou KJ, Silver EJ, Crain EF. Nebulizers vs metered-dose inhalers with spacers for bronchodilator therapy to treat wheezing in children aged 2 to 24 months in a pediatric emergency department. Arch Pediatr Adolesc Med 2003; 157:76-80.

30. Giraud V, Roche N. Misuse of corticosteroid metered-dose inhaler is associated with decreased asthma stability. Eur Respir J 2002; 19:246-51.

31. Iles R, Lister P, Edmunds AT. Crying significantly reduces absorption of aerosolised drug in infants. Arch Dis Child 1999; 81:163-5.

32. Amirav I, Newhouse MT. Aerosol therapy with valved holding chambers in young children: importance of the facemask seal. Pediatrics 2001; 108:389-94. 


\section{SINGAPORE MEDICAL COUNCIL CATEGORY 3B CME PROGRAMME} (Code SMJ 201411A)

1. The inhalation route results in significantly lower systemic absorption and is not recommended as the first-line for acute management of an asthma exacerbation.

2. The current designs of pressurised metered dose inhalers (MDIs) in clinical use have achieved the perfect characteristics to deliver inhalational drugs.

3. Aerosol administration, an alternative to oral preparation, delivers a lower systemic dose directly to the lungs and has a slower onset of action than the oral alternative.

4. Improper assembly of inhalation equipment, leaks around the face mask, and failure to maintain adequate seal are some of the reasons drug availability to the patient is reduced.

5. Shaking and priming before use to ensure effective drug delivery is no longer necessary for the current design of MDIs.

6. Short-acting beta-2 agonists (SABA, also commonly called 'reliever') are made available in shades of blue for easy patient recognition.

7. MDIs are the most effective mode of delivery, consistently delivering up to $80 \%$ of the dose to the lungs with approximately $20 \%$ of wastage deposited in the oropharynx.

8. MDIs may deliver as low as $10 \%$ of the dose to the lungs with poor technique of hand-breath coordination.

9. With up to $80 \%$ of drug delivered through MDIs being deposited in the oropharynx, local side effects (e.g. oral candidiasis for inhaled steroids) and systemic absorption leading to side effects are increased.

10. The correct technique of MDI use is simple and intuitive; more than $90 \%$ of patients above 12 years of age can master the technique by themselves.

11. If the MDI device is properly stored with the stem down, there is minimal risk of inadequate dose delivered even if it is not adequately shaken prior to use.

12. Infrequent users of $\mathrm{MDI}$ devices with manual dose counters risk having an empty device during an acute exacerbation.

13. Common errors in the use of MDI devices include failure to shake it, rapid inspiration, multiple actuations during one inhalation, and inadequate breath holding.

14. It has been demonstrated that the use of a spacer with MDI produces a statistically significant increase in lung-drug deposition compared to using only an MDI with good technique.

15. Drug delivery with a spacer may be reduced if there are errors of assembly, valve dysfunction, delays between actuation and inhalation, and electrostatic charges in an unprimed new chamber device.

16. Younger children need a fitting facemask attached to the mouthpiece to produce a tight seal for effective administration of aerosol medication.

17. The 2013 Cochrane systematic review concluded that there was no difference in treatment outcomes between the use of an MDI with spacer and a nebuliser, for SABA use in children and adults in various settings.

18. Global Initiative for Asthma and British Thoracic Society guidelines now recommend the use of MDI+S (instead of nebulisers) for the management of acute mild to moderate wheeze in children.

19. Due to the lack of cooperation and coordination in very young children, oral SABA, namely syrup salbutamol, is still recommended by most international guidelines for the management of acute wheeze in children.

20. Current evidence for the use of $\mathrm{MDI}+\mathrm{S}$ for SABA delivery does not include severe life-threatening wheeze exacerbations; these cases should be managed in the hospital setting with appropriate expertise and intensive care backup.

\section{Doctor's particulars:}

Name in full

MCR number

Specialty:

Email address

\section{SUBMISSION INSTRUCTIONS:}

(1) Log on at the SMJ website: http://www.sma.org.sg/publications/smjcurrentissue.aspx and select the appropriate set of questions. (2) Provide your name, email address and MCR number. (3) Select your answers and click "Submit".

RESULTS:

(1) Answers will be published in the SMJ January 2015 issue. (2) The MCR numbers of successful candidates will be posted online at the SMJ website by 2 January 2015. (3) Passing mark is $60 \%$. No mark will be deducted for incorrect answers. (4) The SMJ editorial office will submit the list of successful candidates to the Singapore Medical Council. (5) One CME point is awarded for successful candidates.

Deadline for submission: (November 2014 SMJ 3B CME programme): 12 noon, 26 December 2014. 